\title{
Keeping or catching up? Population dynamics and education in Africa
}

\author{
Grace Chisamya ${ }^{1}$ and Adrian Gauci ${ }^{2}$ \\ agauci@uneca.org
}

\begin{abstract}
Africa will account for 80 percent of the 4 billion increase in world population by 2100 . A demographic transition with an increase in its working age population provides a window of opportunity which if reaped will lead to a "demographic dividend" for accelerated growth. In Africa, declining mortality yet combined with high fertility rates constitute unusual population dynamics of developing countries. The dividend is underpinned by adequate skill profiles. Using secondary data sources on education, population trends and fiscal allocation this paper shows that keeping up with increased student intake has somewhat compromised quality of education and adequate skills. In particular the fiscal allocation to education seems not to be aligned to increased student intake further contributing to the challenge of educational quality. The results show that population change contribute only 6 percent change in educational unit allocation thus compromising the possible dividend.
\end{abstract}

Keywords: population dynamics, education quality, fiscal allocation

\section{Introduction}

In the last decade, African economies recorded sustained and impressive economic growth. High global commodity prices, increased domestic demand, and improved economic governance and management, among others, accounted for this strong economic performance. Despite the remarkable economic performance and progress, the continent remains home to the world's highest proportion of poor people, with some noteworthy performance in improving its social outcomes, particularly in education.

Latest figures show that over $68 \%$ of the 25 African countries with complete education data register at least $75 \%$ of primary school enrolment. This has resulted in an average youth literacy rate of $69.61 \%$ by 2012 (ECA 2015). Yet the conversion in job opportunities remains scarce with youth unemployment in 2012 estimated at $23.7 \%$ for North Africa and II.8\% for Sub-Saharan Africa (ILO 20I3).

The challenge confronting Africa is, therefore, not only to maintain the rapid economic growth, but to transform it into sustained and inclusive development. A critical component of this transformation is a demographic change generally from high rates of births and deaths to low birth rates and high life expectancy (Timmer 2008). Indeed, the potential of the youthful working age proportion of Africa's population currently representing $54 \%$ and expected to peak by 2090 at $64 \%$ is expected to generate productivity gains and economic growth. The demographic feature of structural transformation harnesses the link between population dynamics and development (ICPD 20I3). However, the productivity gains expressed as a demographic dividend are underpinned by the provision of educational assets to the young population. The focus so far on primary education in Africa has led to significant strides and primary school demand reflected in the exponential increase of the number of children enrolled in primary school from 62 million in 1990 to I 49 million in 2012 (UIS 20I4).

This increase in student uptake has challenged the positive effects of education on economic growth. This takes on increased resonance given the new global Agenda 2030 and Africa's Agenda 2063 both proposing transformation of economies as their cornerstone and specifically the endorsement of secondary schooling for all.

This paper will analyze how population dynamics currently in force in Africa are restricting quality outcomes of primary education. In particular, the education budget whilst generally on the increase in Africa is not catching up with increased demand. This paper will use secondary data sources to evaluate population dynamics and its link to quality education at the primary level. This paper will use country 
examples to provide further empirical grounding on the population-education link.

The paper is divided into four complementary sections. Section I provides a short literature review and theoretical framework, Section II data and methodology. Section III presents some results on how fiscal allocation to quality education is inadequate Section IV discusses the results obtained. Section $\mathrm{V}$ finally points towards some key policy recommendations.

\section{Section I: Literature review and theoretical framework}

The link between population dynamics and economic growth has had a chequered history particularly in development economics. In the 1960s and 70s, population growth in developing countries stemmed socio-economic development (McNamara 1973). The Malthusian inspired idea was that food supply could not stay ahead of population growth in the long-run (Perkins et al, 2006).

This debate took a more policy oriented turn in the 1990s culminating in Agenda 2030. It is not population growth that is the important feature of development, but its constituent parts. What does emerge is that age structures and decomposed population dynamics have more explanatory force in development (Drummond at al, 20|4).

Africa's population dynamics present some peculiar features. Compared to other regions, Africa starts its demographic transition at a much lower base, the transition is longer, and the peak around 2090 is at a somewhat lower level than other regions. Owing to a multiplicity of factors that lie outside the scope of this paper, in Africa the demographic transition did not start until the mid-1980s. Additionally, the pace of Africa's transition is somewhat slower-about three generations compared to one generation for other developing regions. On current trends, Africa is expected to have a higher share of working age population than North America and Europe in the next two decades, and the highest among all continents by 2060 (Drummond et al, 20|4).

This leads to two possibly contradictory phenomenon. The first is when the working age group is a large proportion of the total population and production is larger than consumption. Countries with heavy concentrations of populations in the working ages have an inherent advantage to produce high levels of per capita income (Mason 2003). The length and pace of this first transition is dependent on the changes over time of fertility and life expectancy. This so called demographic dividend period is quite long, lasting five decades or more, but eventually 2576 lower fertility reduces the growth rate of the labor force, while continuing improvements in life expectancy of the elderly population. Now, other things being equal, per capita income grows more slowly and the first dividend turns negative.

The second is, during the first phase of the demographic transition the potential in productivity gains of a large working age proportion of the population is predicated on adequate assetseducation and health- that are translated into improvements in production. The gains from the dividend are dependent on the level of human capital, and the fact that Africa's average years of schooling of 5.4 years in 2010 is still below that of Europe and North America in 1960. For Africa, countries at lower levels of education have had a decline in growth following the increase in their working age population. However, countries that have invested in education, have been able to reverse this effect and benefit from a positive dividend (Drummond et al. 20I4).

In this regard East Asia success stories in transforming their economies in the 1970s was based on the right combination of the role of human capital and population dynamics then prevailing. Between 1960 and 1990, the working age proportion of the population grew by $25 \%$ more than the general population. Furthermore, this was complemented by a drop in fertility rates. Within a period of two to three decades, the total fertility rate of East Asia dropped from six births per woman to two births per woman. This meant smaller classroom sizes and although fiscal allocation to education did not increase substantially allocation per unit did and was one of the drivers of improved quality of educational output (Mason 2003).

The link between economic growth and education on the other hand has had a long history. In the mid1980s, a group of growth favored a model that replaced the exogenous growth variable (unexplained technical progress) with a model in which the key determinants of growth were explicit in the model (Lucas 1988, Romer 1986). The endogenous growth model had important theoretical implications and empirical studies on growth and human development (Romer 1990, Pissaridies 2000). The basic idea is that growth of incomes alone does not capture the development aspect of improved welfare for population.

The measurement of education on growth can be proxied through secondary education generally using enrollment figures (Carlin 2013; Martin-Retortillo 20I4). This has particular importance as secondary education is some sort of recognition of skill acquisition for labour markets currently proposed in http://aps.journals.ac.za 
the global agenda 2030(UN 2013). Yet the low enrolment figures standing at about 45-50 percent on the continent do not truly reflect Africa's educational outputs (UNESCO 20I4).

Finally, literacy rates as an outcome of Africa's current educational systems have also been used to gauge the impact of human capital. The replacement of the enrolment and average years of education by a more result based outcome literacy seems to combine two features of the link between education and economic growth. Literacy as an end point of educational outputs attests to the quality of the production cycle. Quality concerns have emerged particularly in the African context partly driven by the quantity targets of the previous MDG framework. This can be schematically represented in Figure I
The pertinence and relevance of educational skills imparted becomes an important aspect of quality as expressed in job opportunities.

A theoretical framework chosen for the purposes of this paper stems from the literature that links population dynamics to economic growth and development. This paper, whilst recognizing the multifaceted nature of this link, has selected the fiscal allocation to education variable to assess the link between population dynamics and schooling quality.

below:

Population dynamics

Population growth

Age structure

Fertility and mortality rates

Education

Fiscal allocation

Enrolment,completion,literacy

Skills for labour markets

Productivity gains and economic growth

The framework suggested is not exhaustive but deals with some aspects of population dynamics such as population growth, age structure and fertility rates. Similarly, it looks at some aspects of education particularly enrolment, completion and literacy. This is matched to fiscal allocation and education quality concerns as the result chain of improved economic growth.

\section{Section II Data and methodology}

The research presented in this paper is mainly based on secondary data from UNESCO, UN Population Division and World Development Indicators. This paper presents the trends in fertility and mortality; these being the main determinants of population growth and influencing the age structure. The paper http://aps.journals.ac.za further analyzes trends in education quality by looking at a number of variables.

This paper's contribution to the quality of education policy debate in Africa is based on analyzing the changes in primary school age group population over a two year groupings 2005-2010 and 2010-20I5. These aggregate were chosen for observed acceleration in student intake post 2005. For achievement, we computed selected results on 6 African countries from a learning barometer survey covering 28 African countries and 78 percent of primary school aged children. There are limits to this data in that the assumption is official age groups are used. One of the discerning characteristics of African primary school enrolment is that late age entry is very common and indeed is one of the drivers of low 
completion (ECA 20I3). However data of official age group and its change over time still indicates direction and demographic movements sufficiently.

In terms of fiscal allocation, this paper has utilized the change in unit expenditure for primary education over the same period. The unit expenditure obtained from UIS and WDI was computed as an average over the years of reference. This allowed any time lapse factor in changes in unit cost decided by national authorities. This also provided the data for all African countries that could be used for country specific policies that are currently outside the scope of this paper.

\section{Section III: Results}

\section{Population Dynamics}

Africa's population has steadily increased since the 1950's. The population has grown from 632 million in 1990 to 1.2 billion in 2015. The continent is currently home to 16 percent of the world's population of 7.3 billion people; making it the second most populated region globally-after Asia. Africa's population is projected to increase to 2.4 billion in 2050. The UN World Population Prospects, the 2015 Revision indicate that Africa is the fastest-growing continent, growing at 2.55 percent annually for the period 2010 to 2015 .

In terms of age structure, Africa is said to be the youngest continent. Forty-one percent of the region's population is under 15 years old and a further 19 percent is between 15 and 24 years old. The young age structure nature of Africa's population is evidenced in the population pyramid of 2015 below that has a broad base (ECA 20I6). This age structure pose as both a challenge in terms of ensuring provision of education and other services and an opportunity if proper investments are made to lead to a window of opportunity for a demographic dividend.

Figure 2: Population pyramid Africa (20I5)

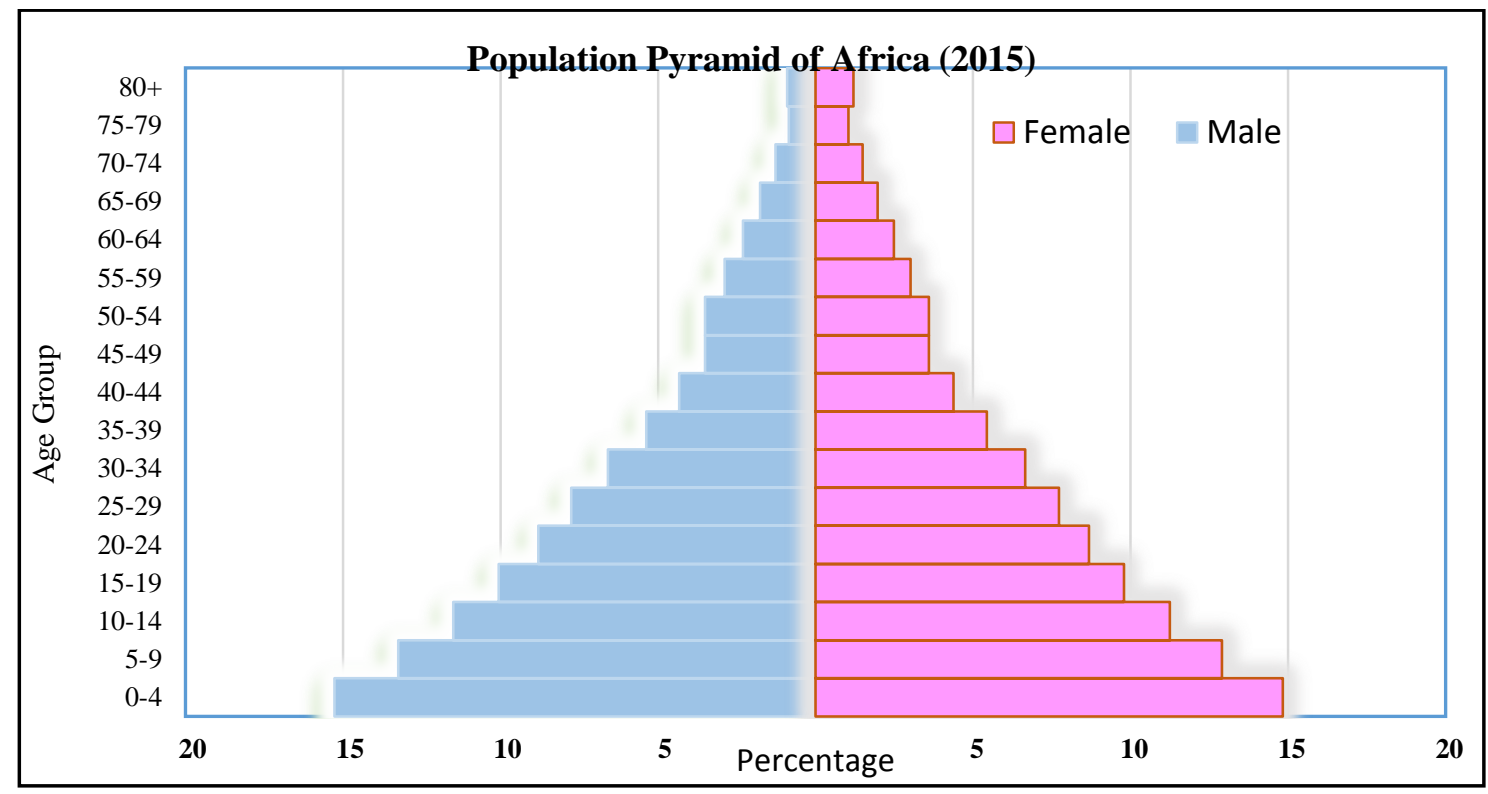

Source: Authors' computations on UN DESA, 2015

Total fertility rate has declined in all regions of the world including Africa. Fertility is the highest in Africa between the periods 2010-2015, estimated at 4.7 children per woman; a decline from 4.9 in 20052010. Notwithstanding, overall fertility will decline, projections for the period 2025-2030 and 2045-2050, show that top ten countries with the highest fertility will be in Africa. The pace of fertility decline varies within the continent though. Africa has made significant progress in reducing under-five mortality.
The UN estimates that between 2000-2005 and 2010-2015, 42 out of 57 countries reduced under five mortality by 20 percent or more. The absolute numbers of children aged below 15 is increasing and estimated at 486 million in 2015. This implies that the continent will see an increased proportion of young people in the coming years before it starts to decline by 2065 . Although Africa's fertility is declining which in the long run will result into declining population, the effects are estimated over the long term 
(Herrmann 20I5). The UN anticipate that the African population will still be young for some time before it starts to age and supplying the young people with the right skills is a necessity for positive spill overs to development.

\section{Education and its quality}

The relationship between population change and change in expenditure per unit at primary school provides some interesting points (See Figure 3). The unit cost right hand axis shows a low allocation practically across all countries and this seems to be unrelated to changes in population on the left hand side axis. In 2005-2010 the trend of unit cost is somewhat flat showing very little change over time and possibly keeping up with increased intake without devoting major resources to quality. The correlation between population and expenditure lies at 3 percent and shows how notwithstanding the large increase in student intake population counts little in determining allocation.

Figure 3: Change in Primary School Student Population and Government Expenditure per Primary Education 2005-2010

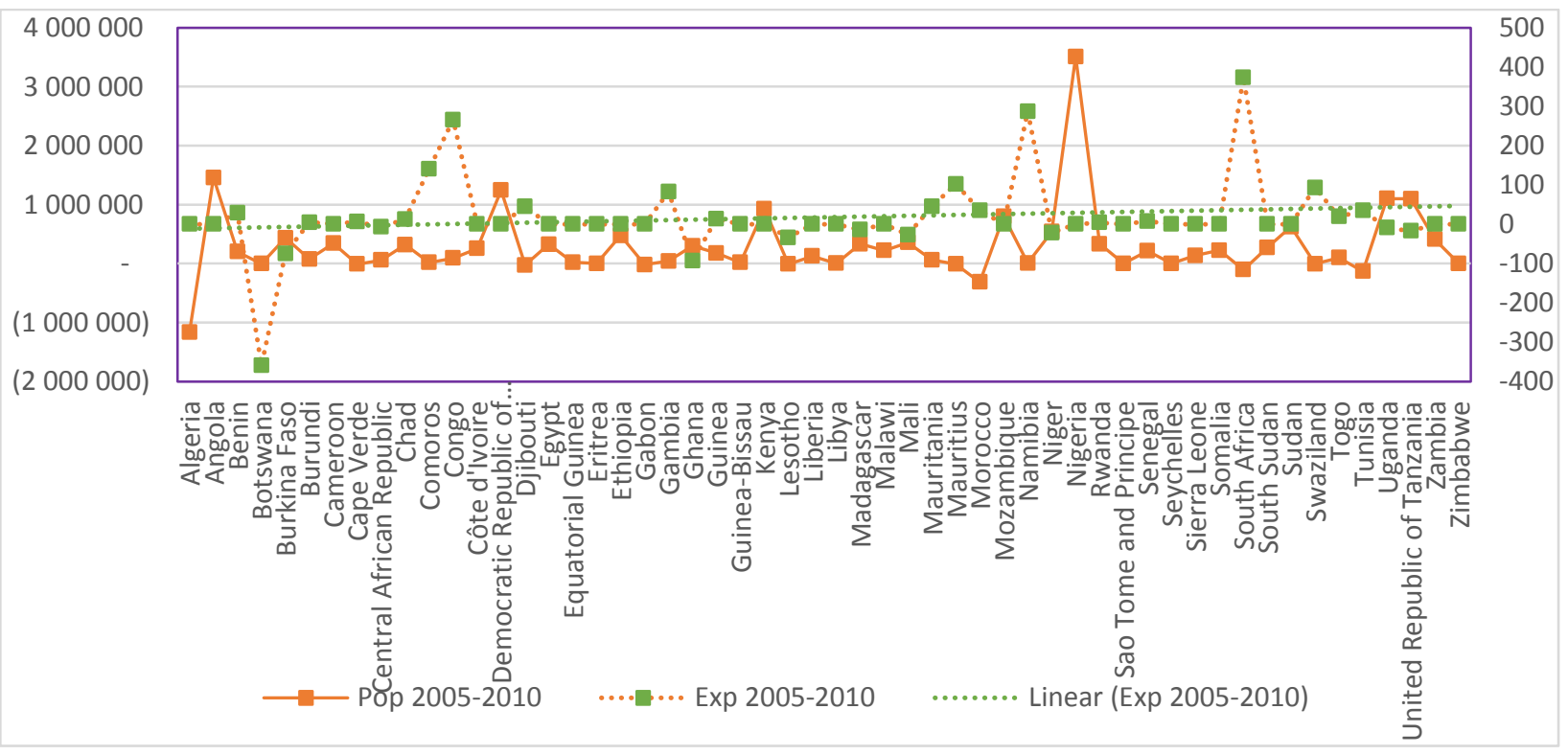

Source: Authors' computations on UIS data

Figure 4 provides the same graph over a more recent period and the status has remained rather static. Population change contributes 6 percent of change in unit expenditure. In both cases there are a number of variables which drive unit cost but population and educational quality remains relevant.

Figure 4: Change in Primary School Student Population and Government Expenditure per Primary Education 2010-20I5 


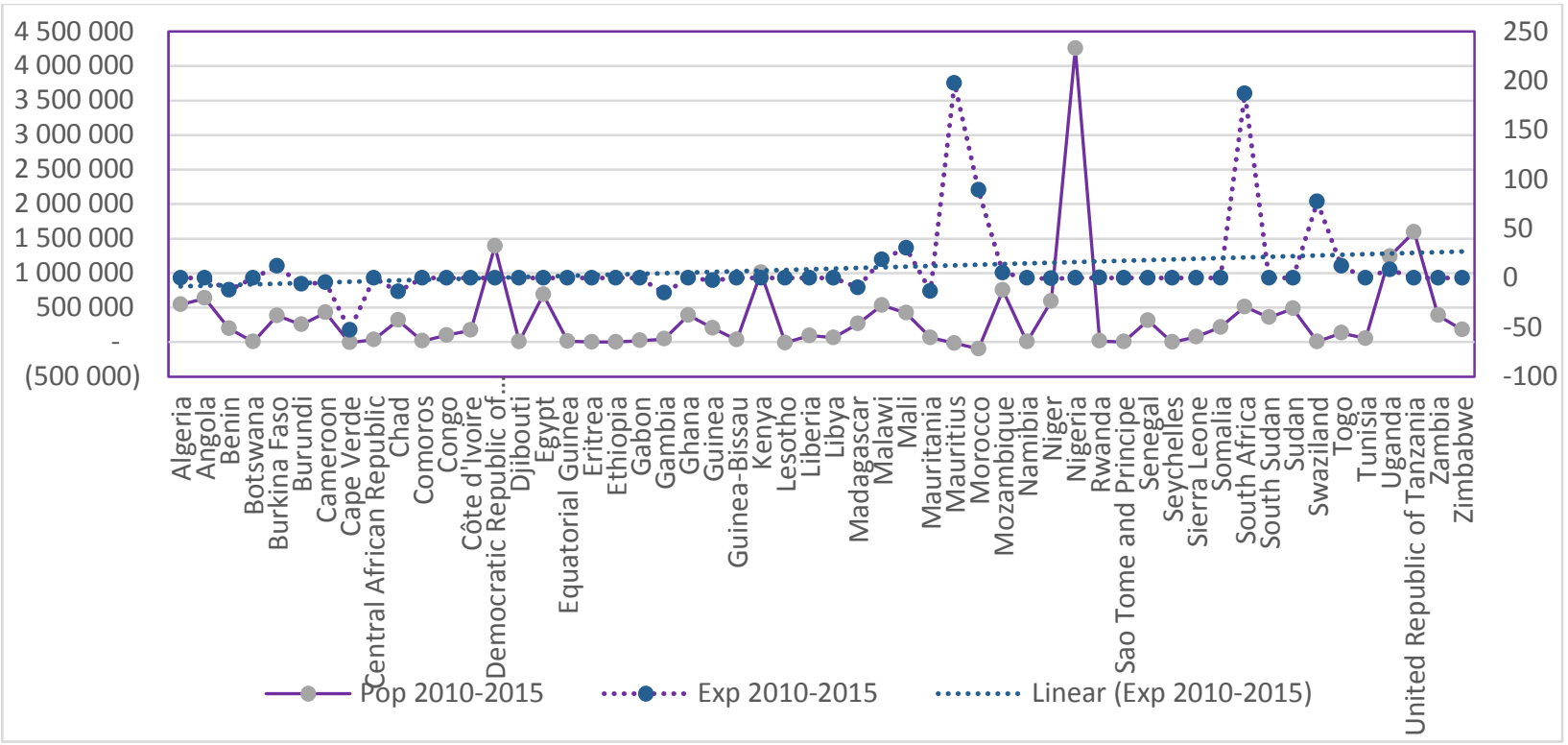

\section{Source: Authors' computations on UIS data}

Some further country specific analysis was done using the same data source. The time periods were slightly modified from 2000 to 2015 to permit linear representation. Furthermore, the countries were divided by their Total Fertility Rates deciding on $>5$ children per fertile woman and $<2$ for low fertile countries on aggregate over the period under consideration.

The results are interesting. In Uganda there has been a positive change in per unit allocation rise in the latest period that seems to take cognizance of the increase in primary school students with an increase in unit allocation of $\$ 9.5$ (See Figure 5). On the other hand, Burundi (See Figure 4) had an increase in student population but a drop in unit allocation. The relationship of population change with an increase in unit allocation are unconnected with possible effects on the quality produced.
Figure 5: Uganda

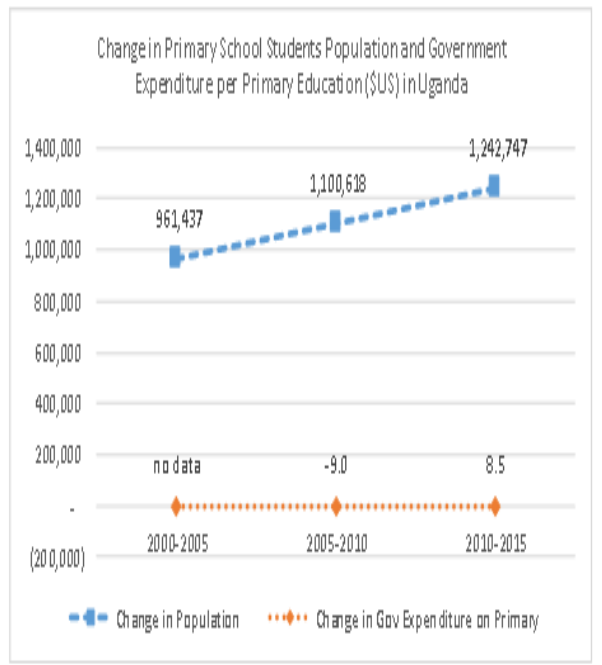

\section{Burundi}

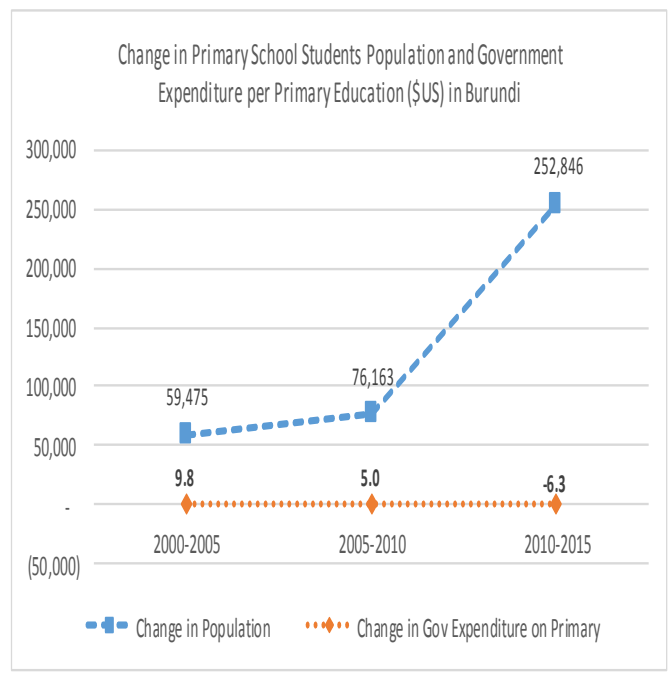

Source: Authors' computation on UIS data

In low fertility countries such as Tunisia and Mauritius (See figure 6) the indications are quite interesting too. In Mauritius, a successfully transformed economy the unit cost change over time has increased positively with a decline in student population. The country seems to follow the population-human capital linkage in East Asia. Tunisia's data is rather difficult to interpret. The period 2000 to 2010 reported decrease in population size with an increase in unit allocation. 


\section{Tunisia}

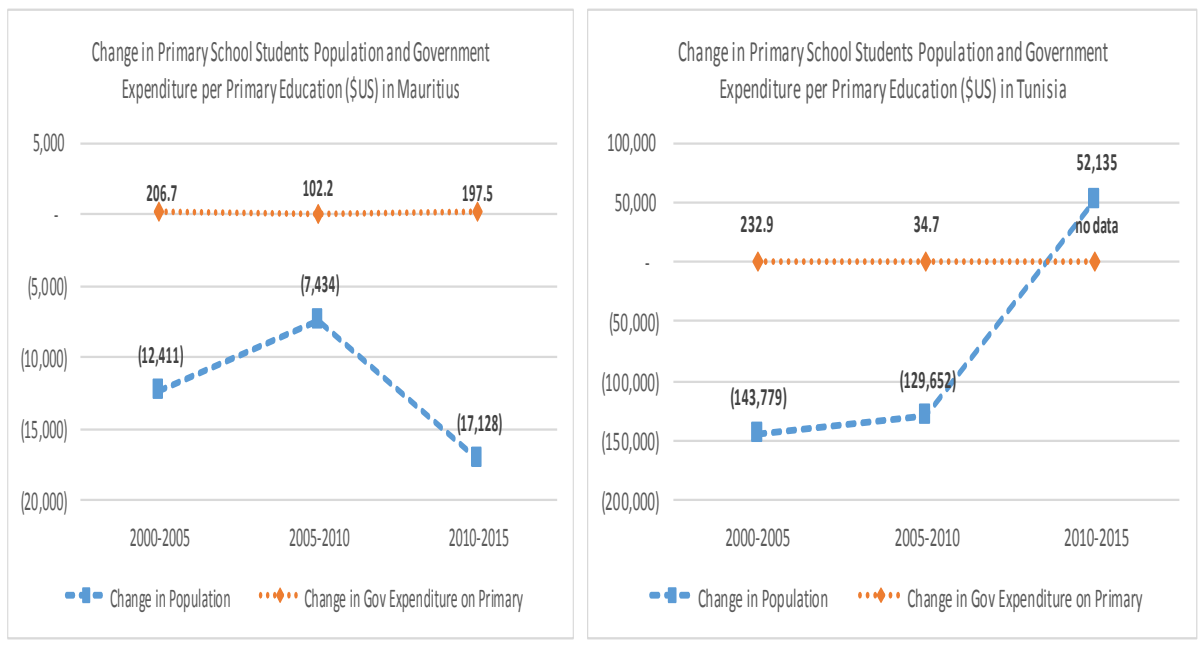

Source: Authors' computation on UIS data

In terms of education, in Africa South of the Sahara progress towards universal primary enrolment was noteworthy-increasing on average the net enrolment rate to primary education by 24 per cent over two decades (1990-201 I), and an accelerated rate 18 per cent between 2000 and 2012. Twenty-five of the 39 African countries (i.e. 64 percent) with data have achieved net enrolment ratios of 80 per cent or above and were on track to achieve the MDG targets.

This increase was brought about through public investment to increase participation while implementing retention-oriented actions (school feeding programmes, cash transfers, etc.) for girls and disadvantaged children and other supply side factors such as school infrastructure. Compared to 2000, there were 35 per cent more school children to accommodate in 2012. The number of children enrolled increased from 62 million in 1990 to 149 million in 2012 (ECA 20I5).

The increase in primary school enrolment has not been matched by completion, denoting quality concerns of importance (See UNESCO 2013). Completion rates have remained at approximately 67 percent of those enrolled at primary schooling. The teacher-student ratio is often used as a proxy for quality of education. The large student intake at primary level has resulted in large classrooms with decreased quality. An often used quality gauge is the teacher: student ratio with the understanding that 2025 students per classroom should be the benchmark (UNESCO 2014). The observations emerging do indicate inadequate ratios. In 201 I (latest data) the pupi/teacher ratio was above $40: 1$ in 26 countries and 23 of those countries were in Sub-Saharan Africa.

http://aps.journals.ac.za
In addition, there has been some regression in this ratio in some African countries due to a significant increase in enrolled children particularly at primary level. For example in Malawi it increased by 20 percent since 1999 and reached 76:I in 20II. This in some African countries has been offset by the enrolment of teachers that have not been through formal training. Indeed, the teacher/pupil ratio increases by 10 students if trained teachers had to be taken into consideration.

In terms of learning outcomes, those completing primary school and acquiring literacy and numeracy skills, quality remains low. In a survey' done using national and regional assessments the results reveal a low standard of learning outcomes (See Figure 7). The scores are particularly low and demonstrate insufficient quality of education, but more importantly the skill barrier in joining the labour market or transiting to secondary education (Watkins 20I3).

\footnotetext{
I Learning Barometer conducted a survey covering 28 African countries and 78 percent of primary school age children. Ethiopia and Nigeria are national assessments SAQMEC III (regional assessment) was used for Malawi and Zambia while PASEC (regional assessment) was used for Benin and Ivory Coast
} 
Figure 6: Learning achievements in selected African countries

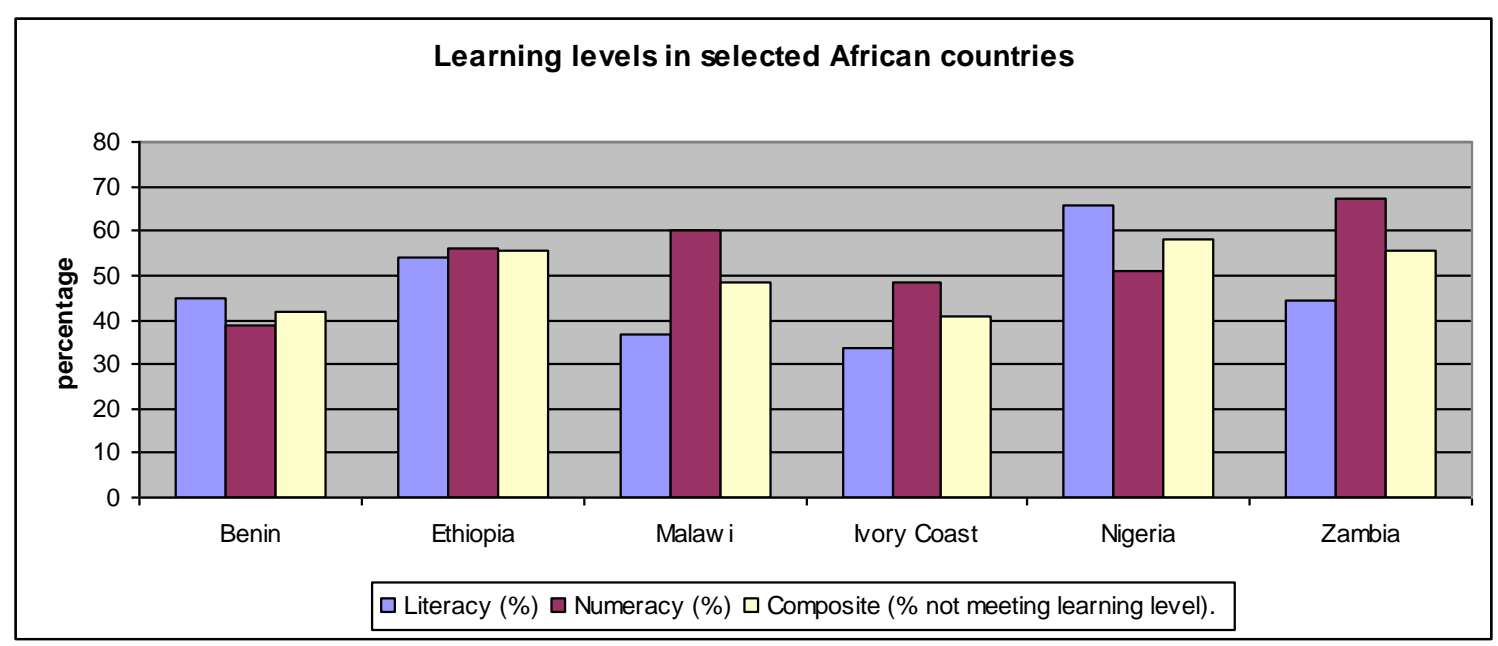

Source: Authors computations on www.brookings.edu 2013

\section{Section III: Discussion}

One of interest to this paper is that the current population dynamics and demand for education has resulted in a mismatch in fiscal allocation to the sector. Hermann (2015) rightly observe that the structure of population matters for development. He argues that population dynamics affects countries opportunities for improving per capita incomes and provision of education, health and infrastructure. The growth of primary school going age group has put pressure on education systems and in turn affected the quality of education.

The slow demographic transition in Africa and the relatively high fertility rates are partly causing the primary schooling system to keep up with intake rather than catching up with quality and ensuring the positive education-growth link.

Unit cost of public expenditure for primary schools in Africa is $\$ 131$, one tenth of world average and significantly lower than the East Asia average of $\$ 1974$ (UNESCO 20I4). The shift in emphasis on universal secondary schooling in the new Agenda 2030 and 2063 makes the quality of primary education imperative for successful transition. The change towards domestic resource mobilization of these development agendas reinforces matching population dynamics and unit fiscal allocation to education.

In Africa the political momentum harnessed in achieving the Millennium Development Goals (MDGs) targets and indicators have made significant contributions to the social and economic development of countries. Indeed, the goals have had unprecedented success in galvanizing international support, not only from governments and intergovernmental bodies, but also from civil society, the private sector, charities, foundations, the media and academia about focusing on a common set of goals that seek to enhance human capabilities (Vandemoortele 2009; Moss 20I0; UN 20II).

The focus on the education goal 2 originally intended as global aspirations became actual targets for countries. Consequently, enrolment of primary school became the target. The noteworthy increase in students enrolled in primary school in Africa, excluding North Africa, was a clear reflection of this policy attention, resulting in limited attention on quality of education. The galvanizing effect of the MDGs and the policy focus on primary school cycles did have an effect of side-lining more comprehensive educational programmes. Thus frameworks such as the Education For all of 2000 in Dakar and the African Union First and Second Decade of Education were not implemented with the same vigour.

\section{Section V: Conclusion and Policy considerations}

The demographic dynamics currently in force on the continent imply an educational policy that is trying to catch up with supply factors. The shift towards keeping up with the imperative of quality education at primary level requires taking population dynamics into account in planning literacy and numeracy skills for all. Therefore, mainstreaming of demographic dynamics in national planning is crucial.

There might be a country-specific need to tradeoff between quantity and quality. However, it is the quality of educational skills that have an impact on growth and structural transformation. Therefore, educational quality must become the policy direction for African countries. 
The new global development agenda and its regional vision indicate quality education, extension to universal secondary schooling and domestic resources. The population dynamics indicate that the alignment of intake quantity to allocation must aim at quality of outcome. This entails raising the unit cost to international standards becomes an important part of this agenda.

Another important policy consideration is reducing fertility through education and other legislative measures. Early child marriage needs to be stemmed and reproductive rights enforced. The drop in fertility through keeping girls in school is a policy option of some interest. As has been observed the education of girls has an effect on decrease in fertility. Economic and other incentives to keep girls in school should be introduced.

\section{Bibliography:}

African Union (2006). Second Decade of Education for Africa (2006-20I5), Addis Ababa, AU

African Union (2006). The African Youth Charter, Addis Ababa, AU

Aquino EM, Almeida M (2009). The role of education level in the intergenerational pattern of adolescent pregnancy in Brazil. Sep;35(3): I39-46.

Bloom, David E., and David Canning (2003). "Contraception and the Celtic tiger". The Economic and Social Review, 34, 229-247.

Carlin W, Schaffer M, and P. Seabright ( 2013). "Soviet power plus electrification: What is the long-run legacy of communism?," Explorations in Economic History, vol. 50, no. I, pp. II6- 147

Domar E (1957). Essays in the Theory of Economic growth, Oxford University Press

Drummond P, Vimal Thakoor, and Shu Yu (2014). "Africa Rising: Harnessing the Demographic Dividend", IMF Working Paper WP/I4/I43

ECA (20II). "Economic transformation in Africa: Drivers, Challenges and Options" presented at Conference of Ministers of Finance

ECA (20II). Economic Report on Africa, Addis Ababa

ECA (2016). The Demographic Profile of African countries, Addis Ababa

Herrmann, M. (Ed.)(20I5). "Consequential Omissions, How demography shapes development-Lessons from MDGs for the SDGs", Berlin, Berlin Institute for Population and Development

ILO(20I3). Global employment report, Geneva

Keats, A. (20/4). "Women's Schooling, Fertility, and Child Health Outcomes: Evidence from Uganda's http://aps.journals.ac.za
Free Primary Education Program", accessed at http://akeats.faculty.wesleyan.edu/files/20 I 4/02/U ganda_paper_Keats_14feb I4.pdf

Kedir, A. and Y. Bani(2014 ). "Growth, Volatility and Education: panel evidence from developing countries" Journal of Social Sciences \& Humanities (JSSH).

Krueger, A.,M. Lindahl (200I). "Education for Growth: Why and for whom?" Journal of Economic Literature, Vol. 39, pp. I I 0 I-I I 36

Kuznets S (1966). Modern Economic Growth: Rate, Structure and Spread. New Haven and London: Yale University Press

Lin J (20I2). Structural Economics A Framework for Rethinking Development and policy, World Bank, Washington

Lutz, W. (20I5). "Why education should top the development agenda",

http://blog.iiasa.ac.at/20 I5/09/25/why-educationshould-top-the-development-agenda/ accessed 31 October 2015

Martin-Retortillo M and V. Pinilla (2014)."On the causes of economic growth in europe: why did agricultural labour productivity not converge between 1950 and 2005?," Cliometrica, pp. I \{38, 2014.

Mason A (2003). "Population change and economic development: what have we learned from the East Asia experience?", Applied Population and Policy 2003: I (I) 3-I4

Pissarides C (2000). HUMAN CAPITAL AND GROWTH:A SYNTHESIS REPORT, OECD, Paris

Population Reference Bureau (20II). The Effect of Girls' Education on Health Outcomes: Fact Sheet, accessed at http://www.prb.org/Publications/Media-

Guides/20I I/girls-education-fact-sheet.aspx

Joan Robinson Essays in the Theory of Economic Growth

Timmer $P$ ( 2008). The Structural Transformation and the Changing Role of agriculture in Economic Development: Empirics and Implications. Available from:

http://iisdb.stanford.edu/pubs/22/33/Timmer_wendt_lect ure.pdf

UIS (20|4). UNESCO Information System, Montreal UN (2015). Transforming our World: The 2030 Agenda for Sustainable Development, finalized text for adoption at the 70th Regular Session of the UN General Assembly, New York, UN

UNDESA (2014). World Economic Situation and prospects, New York

UNDESA and UNFPA (20I2). Population dynamics, Thematic Think Piece, UN System Task Team on 
the Post 2015 UN Development Agenda, New York available from http://www.un.org/millenniumgoals/pdf/Think\%2 OPieces/I5_population_dynamics.pdf

UNESCO (1999). Education and Population Dynamics: Mobilizing Minds for a Sustainable Future, Paris, UNESCO, accessed at http://unesdoc.unesco.org/images/00 I I/00 I |63/ | I6355Eo.pdf

UNESCO (2010). Education Counts: Towards the Millennium Development Goals, Paris, UNESCO, accessed

http://unesdoc.unesco.org/images/00 I 9/00 I902/1

90214 e.pdf,
United Nations, Department of Economic and Social Affairs, Population Division (20/5). World Population Prospects: The 2015 Revision, New York, UNDESA

Williamson, J.G., and M. Higgins (200I). "The Accumulation and Demography Connection in East Asia," in Population Change and Economic Development in East Asia: Challenges Met, Opportunities Seized, eds. by Mason A., Chapter 5, Stanford: Stanford University Press.

World Bank (2005). The Construction of a knowledge based society, Washington 